\title{
MicroRNAs in Rheumatoid Arthritis
}

\author{
Angela Ceribelli ${ }^{\mathrm{a}}$, Md A. Nahid ${ }^{\mathrm{a}}$, Minoru Satoh ${ }^{\mathrm{b}}$, and Edward K.L. Chan ${ }^{\mathrm{a}}$ \\ Angela Ceribelli: aceribelli@dental.ufl.edu; Md A. Nahid: manhid@dental.ufl.edu; Minoru Satoh: \\ minoru.satoh@medicine.ufl.edu \\ a Department of Oral Biology, University of Florida, 1395 Center Drive, Gainesville, Florida \\ 32610-0424 \\ b Division of Rheumatology and Clinical Immunology, Department of Medicine, and Department of \\ Pathology, Immunology, and Laboratory Medicine, University of Florida, 1395 Center Drive, \\ Gainesville, Florida 32610-0221
}

\begin{abstract}
Rheumatoid arthritis (RA) is a chronic and severe autoimmune disease that affects joint tissues, bone, and cartilage. However, the pathogenesis of RA is still unclear. Autoantibodies such as rheumatoid factor and anti-cyclic citrullinated peptide are useful tools for early diagnosis, monitoring disease activity, and predicting prognosis. Recently, many groups have focused their attention on the role of microRNAs in the pathogenesis of RA, as well as a potential biomarker to monitor RA. In fact, the expression of some microRNAs, such as miR-146a, is upregulated in different cell types and tissues in RA patients. MicroRNAs in RA could also be considered as possible future targets for new therapeutic approaches.
\end{abstract}

\section{Keywords}

autoimmunity; innate immunity; rheumatoid arthritis; microRNA; miR-146a

\section{Introduction}

Rheumatoid arthritis (RA) is a systemic autoimmune disorder mainly characterized by the inflammation of synovial tissue that can lead to destruction of bone and cartilage, and eventual disability [1,2]. The mechanisms involved in disease initiation and progression are still incompletely understood, as RA has a complex component induced by several genes, that interact together with environmental and stochastic factors [1]. In recent years, RA has often been divided into subsets according to a specific autoantibody profile, linked to the presence or absence of rheumatoid factor and anti-cyclic citrullinated peptide (anti-CCP) antibodies [3,4]. Recent reports show that joint destruction, cardiovascular comorbidities and other extra-articular manifestations are prominent in the subset of patients positive for both rheumatoid factor and anti-CCP antibodies [5,6]. For anti-CCP positive RA patients a series of inflammatory cascades are active [1]. Eventually, this inflammatory milieu could be transformed into a destructive action on joints, which also leads to activated immune

(C) 2011 Federation of European Biochemical Societies. Published by Elsevier B.V. All rights reserved.

Address correspondence and reprint requests to: Edward K.L. Chan, Ph.D., Department of Oral Biology, University of Florida, 1395 Center Drive, Gainesville, FL 32610-0424. Tel: 352-273-8849. Fax: 352-273-8829. echan@ufl.edu.

Publisher's Disclaimer: This is a PDF file of an unedited manuscript that has been accepted for publication. As a service to our customers we are providing this early version of the manuscript. The manuscript will undergo copyediting, typesetting, and review of the resulting proof before it is published in its final citable form. Please note that during the production process errors may be discovered which could affect the content, and all legal disclaimers that apply to the journal pertain. 
cells, imbalances in the regulation of cytokines and other inflammatory mediators $[7,8]$. In the last decade, many therapies have been developed to target specific components of the inflammatory and autoimmune response in RA. In particular, anti-TNF (infliximab, etanercept, adalimumab), anti-IL-1 (anakinra), anti-IL-6 (tocilizumab), anti-CD20 agents (rituximab), and anti-CTLA4 (abatacept) therapies have proved to be effective [1]. Unfortunately, the response to these drugs is variable and the outcome cannot be predicted before starting the therapy; they also are linked to increased risk for infection and cancer [9$11]$.

Many investigators have focused their attention on the role of microRNAs (miRNAs) in the immune response [12]. MiRNAs are short (about 21 nucleotides long) non-coding RNAs that can influence messenger RNA (mRNA) processing at the post-transcriptional level. Using standard nomenclature, miRNA name is assigned to experimentally confirmed new miRNAs [13]. In particular, the abbreviation "miR" refers to the mature form and this prefix is then followed by a dash and a number, which follows the order of naming the RNA. For example, miR-132 was named and likely discovered before miR-155. MiRNAs with the same seed sequence (nucleotide position 2-7), except for one or two nucleotides, are annotated with an additional lower case letter, as in the case of miR-146a and miR-146b.

\section{Biogenesis of miRNA}

As shown in Figure 1, miRNAs are transcribed from their respective gene loci as primary miRNA (pri-miRNA). Genes encoding miRNAs exist as single genes, gene clusters, and within introns of other genes. The maturation of pri-miRNA starts in the nucleus, where the enzyme Drosha and its associated protein DGCR8 process it into a 70-nucleotide precursor miRNA (pre-miRNA) [14,15]. An alternative pathway for the biogenesis of a very small subset of miRNAs known as mirtrons has also been described. In brief, these miRNAs are encoded in short introns with hairpin-forming potential that can be spliced into pre-miRNA using existing mRNA splicing machinery, and thus bypass the requirement for the Drosha/ DGCR8 processing step [16]. The pre-miRNA is then exported to the cytoplasm, and is further processed by another enzyme, Dicer, which is a ribonuclease III (RNAse III) enzyme like Drosha. At this stage, the pre-miRNA is approximately 21 nucleotides long and is a duplex, composed of a guide strand and a passenger strand (indicated as miRNA star form, miRNA*). The miRNA is now ready to be loaded onto Argonaute (Ago), one of the key components of the RNA-induced silencing complex (RISC). There are four Ago proteins in mammals (Ago 1-Ago 4), but Ago2 is the most studied for its role in the miRNA pathway $[17,18]$. Depending on the thermodynamic of a given miRNA-miRNA* duplex, its loading onto the miRNA binding pocket of Ago2 may favor recruitment and retention of one strand over the other. The passenger strand is ejected and the Ago2-bound strand serves as the guiding strand (also known as the anti-sense strand). The conventional designation has miRNA as the favor guiding strand and miRNA* as the passenger strand. However, recent studies have reported that some miRNA* act as guiding strands with interesting biological functions [19]. Thus, Ago2 protects and maintains the stability of the bound mature miRNA for recognition of its cognate mRNA target(s), resulting in translation repression and/or degradation. The major pathway summarized in Figure 1 provides an overview in miRNA biogenesis based on the two processing steps requiring Drosha and Dicer, respectively. Note that a number of miRNA have been also detected in high-throughput sequencing of RNA species in Drosha -/- and Dicer -/- mouse embroyonic stem cells [20]. The advance in sequencing has also allowed the identification of certain functional miRNAs that bypass the Dicer processing step [21]. The significance of these Drosha-independent or Dicer-

independent small RNA in mammalian somatic cells remains to be defined in future studies. The gene expression of miRNA is now known to be regulated like other genes at the 
transcriptional level, Drosha-mediated processing step, RNA editing of transcript, and control of decay (for recent review, see [22]).

The key protein responsible for translation repression is GW182, which is an $182 \mathrm{kDa}$ protein rich in glycine-tryptophan (GW) dipeptide motif [23]. Recent data show that GW182 has multiple non-overlapping GW-rich domains that bind Ago2 [24] and at least two independent, divergent translation repression domains [25]. GW182 and Ago proteins are localized in cytoplasmic foci known as GW bodies (GWBs) [23,26]. Interestingly, both GW182 and Ago2 are targets for autoantibodies $[18,27,28]$ and the first identification of the cytoplasmic foci GWBs was made using human autoantibodies as probes [18]. The size and number of GWBs are correlated to increase in RNA interference activity in cells by either siRNA [29] or miRNA [30,31]. GWBs are also known as mammalian processing bodies or $\mathrm{P}$ bodies. It has also been reported that the formation of these large foci can be a consequence rather than a cause of the siRNA/miRNA activity [32].

\section{The miRNA-mRNA interaction}

For the miRNA-mRNA interaction, one important requirement is the continuous and perfect base pairing of the miRNA seed region (nucleotides 2-7) [33]. This interaction normally lies in the 3'-untranslated region (UTR) and it is required for effective repression of translation [34]. However, in some cases the miRNA-mRNA interaction can take place at the 5'-UTR, leading to enhancement in translation [35]. A number of interesting studies have now shown that protein coding regions can also be targeted by miRNA, leading to translational repression and degradation [36-38]. This has some practical consequences for investigations into the targets for specific miRNAs, since to date most algorithms or software available do not examine sequences other than those in the $3^{\prime}$-UTR. Another new development is the identification of miRNA "centered sites" that expand the miRNA targeting code by utilizing centered pairings instead of seed sequence matches [39]. The feature of centered site-based interaction between miRNA and mRNA target $3^{\prime}$-UTR is that perfect pairing in the seed region or a $3^{\prime}$-compensatory pairing, is not required, instead it contains at least 11 contiguous nucleotides that pair to a miRNA at position 4-14 or 5-15 [39]. This work has been published recently and clearly none of the available software, including the popular TargetScan version 5.1 [40], is programmed to detect this type of interaction.

Another practical aspect in the analysis of miRNA-mRNA interaction, beyond employing bioinformatics algorithms, has to take into consideration other important factors such as cellular context, association of cellular RNA-binding proteins, and possibly the 3D structure of mRNA. In fact, many known mRNA-binding proteins modulate mRNA function in a dynamic way in order to maintain structural and functional integrity [41]. The most common algorithms, such as TargetScan, as mentioned above, do not consider structural aspects, such as the presence of cytoplasmic mRNA-binding proteins and the three-dimensional folding of the target mRNAs that may block access to certain "predicted" miRNA binding sites. For this reason, at least two methods known as called HITS-CLIP [42] and PAR-CLIP [43] have been developed, to directly identify protein-RNA interactions via covalently crosslinking of native RNA-binding protein-RNA complexes, including Ago protein-miRNA-mRNA complexes; the sequences of relevant miRNA-mRNA interactions are then determined by deep sequencing. This is applicable not only for in vitro, but also for in vivo experiments, as for the validation of genome-wide interaction of miR-124a in the mouse brain [42]. Identification of defined miRNA-mRNA interaction remains an important focus to understand control in gene expression. miRNA are able to induce translational repression or mRNA degradation, and in this way they are thought to control more than $50 \%$ of all protein-coding mammalian genes [22]. A recent article describes how most miRNAmediated regulation leads to target mRNA degradation [44]. 


\section{2. miRNAs and the immune system}

MiRNAs have been found in virtually all species, and over 800 human miRNAs have been detected so far [22]. MiRNAs play an important role in many different cellular processes, and their dysregulation is described in various pathologic conditions, such as cancer. The role of miRNAs in normal immune functions is important at different levels. It has been shown that miRNAs can control many immune processes, including granulopoiesis, $\mathrm{T}$ - and B-cell development and maturation, antigen presentation, Toll-like receptor (TLR) signaling cascade and cytokine production, immunoglobulin class-switch recombination in B-cells, and T-cell receptor (TCR) signaling [45]. Some miRNAs have shown a specific role in the regulation of normal and abnormal immune functions, like miR-125b, miR-146a, miR-150, miR-155, miR-181a/b, and miR-223 (reviewed in [14]). In recent years, interest in miR-146a has increased, because this miRNA is important in the negative regulation of acute inflammatory responses during activation of innate immunity [46]. Changes in miR-146a expression are observed in human diseases, such as inflammatory and autoimmune diseases, viral infections, sepsis, multiorgan failure, and cancer [46]. There are two known isoforms of miR-146 in human, miR-146a and miR-146b. They are encoded by different genes, from chromosome 5 and 10, respectively [47], and they probably play different roles based on their differential expression in tissues and cell types. As mentioned before, the alteration in miR-146a expression is an important event in the pathogenesis of many human diseases. This happens in particular through post-transcriptional inhibition of specific target genes, like IRAK1 (IL-1 receptor-associated kinase 1) and TRAF6 (tumor necrosis factor receptor-associated factor 6) [46,48]. With the aim to identify the involvement of miRNAs in the regulation of the innate immune response, previous investigators found an increase of miR-146a in human monocyte cell line THP-1 cells, when stimulated with lipopolysaccharide (LPS, or endotoxin) [48]. LPS is a major outer membrane component of Gram-negative bacteria, and a very potent immunostimulatory molecule. When LPS is in contact with the innate immune system, which is known to be the primary defense against microbial infections, it leads to the production of cytokines, including TNF- $\alpha$, IL-6, and IL-10 [49]. This mechanism is activated through the NF- $\mathrm{KB}$ pathway, with the aim to control the growth and dissemination of pathogens and thereby to activate the adaptive immune response as needed, as shown in Figure 2A. In the case of systemic dissemination of the infection (as in bacteremia or sepsis), immune cells from septic patients assume a refractory state to further LPS challenges, and they interrupt the production of inflammatory mediators [50,51]. This phenomenon is known as "endotoxin tolerance" and it is a very important host mechanism aimed at limiting inflammatory damage caused by the overactivation of the immune system induced by continuous exposure to LPS or other bacterial TLR ligands [51]. Our studies show that miR-146a plays a key role in innate immunity [52,53]. In the first report, following LPS stimulation of THP-1 cells, we have reported that TNF- $\alpha$ production increases quickly for up to 4 hours and then gradually decreases, as expected, whereas the miR-146a level begins to go up at about 4 hours, maintaining this overproduction for the next 24 hours [52]. LPS-tolerized cells were able to regain control of the TNF- $\alpha$ production 22 hours after LPS removal, and this was correlated to the decrease in miR-146a level [52]. To rule out other players in the complex TLR signaling pathways, the key points are that up-regulation via transfection of miR-146amimic alone can mimic LPS priming to induce tolerance, and knockdown of miR-146a via transfection of a specific antagomir (anti-miR-146a) diminishes LPS tolerance [52]. The overall results of this study show that miR-146a is a critical factor in the mechanisms of endotoxin tolerance, as shown in Figure 2 (panels A and B). TLR signaling is governed by the MyD88-dependent and MyD88-independent (also known as TRIF) pathways [54]. Interestingly, except for TLR3, all the major TLR-signaling takes place via the MyD88dependent pathway, with the activation of IRAK1, IRAK2, and TRAF6 [55,56]. This leads to further investigation of the role of miR-146a in endotoxin-induced cross-tolerance, as it is 
expected that the elevated level of miR-146a will repress IRAK1, IRAK2, and TRAF6, and thus block all TLR signaling except, perhaps, for TLR3 [53]. LPS priming of immune cells can result in diminished cytokine response after subsequent stimulation with TLR2 ligands. This mechanism is known as "LPS-induced cross-tolerance", which is observed in cells from patients with sepsis [57]. We have also studied the correlation between LPS-induced miR-146a and innate immune response in THP-1 cells, focusing on cytokine production and TLR regulation [53]. Results show that inflammatory response to some TLR (TLR2, TLR4, TLR5) ligands are reduced with the knockdown of miR-146a targets, such as IRAK1 and TRAF6. This validates the regulatory effect of miR-146a on these TLRs signaling, which seems to play a crucial role for in vitro monocyte-based endotoxin-induced cross-tolerance [53].

A new field of investigation for miR-146a is represented by a recent study of its enhanced expression in one experimental murine model of periodontal disease [58]. The maxilla and the spleen from Apo $\mathrm{E}^{-/-}$mice chronically infected orally with polymicrobial P. gingivalis/ T. denticola/T. forsythia were analyzed for miRNA expression. The results show that miR-146a has a persistent association with these periodontal pathogens, suggesting that it may have a modulating effect on chronic periodontal infection. A number of studies have demonstrated an association between RA and periodontal disease [59,60]. In a recent study, the association of RA and periodontal disease has been identified in the third National Health and Nutrition Examination Survey (NHANES III), a nationally representative crosssectional survey of non-institutionalized civilian population [61]. As $P$. gingivalis is one of the major pathogens implicated in periodontitis, it is interesting that the presence of antibodies to $P$. gingivalis is reported to be correlated with anti-CCP antibodies in RA patients and their relatives [62]. The investigators suggest that $P$. gingivalis can break the immune tolerance and induce the production of anti-CCP antibodies, through a mechanism of post-translational citrullination of arginine residues by the bacterial enzyme peptidyl arginine deiminase (PAD). However, the specificity for antibodies to $P$. gingivalis cannot be readily demonstrated as they may arise from cross-reactive antibodies to other bacteria. Furthermore, it is known that the specificity of bacterial PAD is largely restricted to citrullination of terminal-arginine residues which are the same as citrullinated residues as in $\mathrm{CCP}$ or citrullinated peptides generated from mammalian PAD enzymes [63]. In any case, the increased expression of miR-146a in the experimental periodontal model is intriguing, because the same miRNA has been reported as being elevated in many RA studies (see below).

Beside innate immunity, adaptive immune response also can be influenced by miR-146a [64]. It has been shown that miR-146a modulates activation-induced cell death (AICD) as an anti-apoptotic factor, and one target of miR-146a is the Fas-associated death domain (FADD) [64]. Furthermore, miR-146a is able to impair the production of AP-1 transcriptional activator protein and IL-2 induced by TCR engagement, and this is another element supporting the role of miR-146a in the modulation of adaptive immunity [64].

Another recent report shows that miR-146a is able to influence the immune response mediated by T regulatory (Treg) cells [65]. In fact, a deficiency of miR-146a in Treg cells was responsible for breaking immunological tolerance, causing fatal IFN -dependent immune-mediated lesions in different organs in the miR-146a knockout mouse model [65].

\section{3. miRNAs in rheumatoid arthritis}

RA is a chronic autoimmune disease that can severely affect multiple joint structures and synovial membranes [66]. In some cases, it also can be associated with extra-articular manifestations, mainly involving lung, heart and renal functions [1]. Apart from clinical and 
radiological features, autoantibody detection is also important for diagnosis, especially in the early phase of RA [67]. In particular, anti-CCP antibodies are considered to be highly specific for severe erosive RA, and their early identification allows the early diagnosis and treatment of RA patients, who experience better outcomes [67]. Recent studies have supported an important role for miRNAs in RA, and dysregulated miRNA expression seems to contribute to the molecular mechanisms of the disease. As shown in Table 1, aberrant expression of several miRNAs has already been detected in RA, in different cell types, and these miRNAs can regulate specific pathways, thus leading to the inflammatory milieu taking place in RA [68]. In 2008, our group reported the increased expression of some miRNAs (miR-155, miR-146a, miR-132, and miR-16) in PBMCs from RA patients [69]. The levels of expression of TRAF6 and IRAK1, two targets of miR-146a, were not increased in RA patients when compared with control subjects [69]. The repression of these two targets in THP- 1 cells showed a strong reduction of TNF- $\alpha$ level. The conclusions were that miR-146a expression in PBMCs mimics that of RA synovial tissue and fibroblasts, as reported earlier [70,71]. How the up-regulation of miR-146a could be related to the persistent production of inflammatory TNF- $\alpha$ in RA remains unclear. Recently, it has been shown that miR-146a can inhibit osteoclastogenesis, and the administration of doublestranded miR-146a could prevent joint destruction in a collagen-induced arthritis mouse model [72]. As shown in Table 2, the same miRNA has been reported to increase between 1.43 and 4 fold in different cells and tissues in RA, demonstrating consensus in the elevated miR-146a expression associated with the disease [70,71,73]. However, the elevated expression of miR-146a is not specific to RA, as it is also reported in osteoarthritis, specifically in osteoarthritis cartilage after stimulation by IL-1 $\beta$ [74]. Moreover, miR-146a can control knee-joint homeostasis and osteoarthritis-associated algesia, through the reduction of the inflammatory response in the cartilage and synovium [75]. The main advantage of the detection of miR-146a in circulating PBMCs is that this opens the possibility to test it as a biomarker to monitor during the disease course, without the need for invasive surgical procedures to obtain joint tissues and cells for miRNA analysis. As previously mentioned, genetic predisposition is one of the contributing factors involved in RA pathogenesis. One recent work [76] shows that specific polymorphisms in the 3'-UTR of IRAK1, one of the targets of miR-146a, leads to increased susceptibility to developing RA. This observation opens the possibility to study how miRNAs and polymorphisms in their targets can lead to RA in specific ethnic groups and in association with environmental factors.

In RA patients, since 2008, other miRNAs have been detected, each with a specific pattern of expression and a specific role in inflammatory pathways (Table 1). In particular, higher expression of miR-155 was reported in synovial cells and tissues [71]. The increased levels of miR-155 were found to be associated with the repression of MMPs (matrix metalloproteinases) production, thus leading to modulation of joint inflammation. In 2009, another research group identified decreased expression levels of miR-124 in RA synoviocytes [77]. This miRNA is involved in cell proliferation, and these investigators showed that the transfection of miR-124 precursor led to arrest of the cell cycle. Moreover, two targets of miR-124, CDK2 (cyclin-dependent kinase 2) and MCP-1 (monocyte chemotactic protein-1), which are involved in the inflammatory process in RA, are tightly controlled by miR-124. The results showed that miR-124 could be an important regulator of the synovial inflammatory milieu in RA [77]. In the same year, another group identified a new up-regulated miRNA, miR-346, in RA fibroblast-like synoviocytes (RA FLS) [78]. This miRNA was able to indirectly regulate the release of a pro-inflammatory cytokine, IL-18. MiR-346 acts through the indirect inhibition of the Bruton's tyrosine kinase in LPSactivated RA FLS, which is involved in the miR-346-related regulation of IL-18. In 2010, Fulci and colleagues [79] published their results on miRNA analysis in RA patients. They identified the increased expression of miR-223 in CD4+ naïve T lymphocytes. As T 
lymphocytes are considered to play a role in the pathogenesis of RA, these results suggest that miR-223 could target T-cell response and therefore contribute to the onset of the disease. In the same year, Stanczyk published the results of the analysis of another miRNA, miR-203 [80]. Its upregulation in synovial fibroblasts is responsible for increased MMPs and IL-6 production, thus indicating that miR-203 plays a role as pro-inflammatory and joint destructive factor in RA. A recent study also shows that miR-363 and miR-498 are downregulated in CD4+ T cells of RA patients, while miR-146a expression is significantly upregulated [73].

Another important and emerging field of study for autoimmune diseases, including RA, is represented by epigenetics. The three main mechanisms of epigenetic control (DNA methylation, histone modifications, and miRNA regulation) interact in the development of the RA-synovial fibroblast phenotype [81]. RA synoviocytes show epigenetic abnormalities, mainly represented by DNA hypomethylation and histone hyperacetylation, thus leading to synovial proliferation [82]. In RA, synovial cells histone deacetylases overexpression has been demonstrated at the transcriptional level, and the use of histone deacetylase smallinterfering RNA has revealed that this enzyme plays an important role in the synoviocyte proliferation and apoptosis [83]. Another study showed that synoviocyte hyperacetylation was associated with an increase of histone acetyl transferases, without variation of the histone deacetylases [84]. DNA hypomethylation is another epigenetic modification that can occur in RA, leading to the up-regulation of genes coding for growth factors, receptors, adhesion molecules, and other components responsible for the inflammatory milieu and active phenotype of RA-SFs [85]. These observations show that epigenetic control is deficient in RA joint cells, suggesting that broader analysis is required to better understand the role of these mechanisms in the pathogenesis of RA, the identification of epigenetic biomarkers, and the development of specific therapies targeting key molecules of the epigenetic process.

\section{Concluding remarks}

In recent years, the study of miRNAs has become very important due to their role as major regulators of gene expression affecting single or multiple physiological and pathological pathways. Whether this holds true for every miRNA will need to await more extensive analyses. Most studies focus their attention on the mechanisms through which a specific miRNA can influence cell growth and differentiation, cytokine production, or other processes. These results have clarified many aspects linked to various miRNA structures and functioning, but more data are needed as there are still many limitations to clarifying the complete functions for many miRNAs. One problem is that differences in experimental design can favor one mode of repression over another. To further understand the role of miRNAs in disease, it is important to have in vivo studies using mouse models. For example, as specific miRNA knockout mice are becoming available [65], we can have new insights on the role of these miRNAs affecting the disease state. Moreover, different miRNAs are up- or down-regulated, according to the cell type analyzed, and most studies on RA are based on tissue sample analysis. It would be useful to improve the method of miRNA detection in serum or plasma in order to find a possible correlation between miRNA expression and disease activity. This could lead to the use of miRNAs as new diagnostic and therapeutic targets, especially using promoters or inhibitors of specific miRNAs that are involved in RA inflammatory pathways. To date, miR-146a appears to be a key player in RA, and its elevated expression is related to a specific pattern of cytokine expression, so it has become one of the most important miRNAs for future studies in RA, but studies of other relevant miRNAs and their mechanisms involved in RA pathogenesis and disease expression are still needed. 


\section{Acknowledgments}

This work was supported in part by a grant from the Lupus Research Institute and the National Institutes of Health grant AI47859.

\section{Abbreviations}

\begin{tabular}{|c|c|}
\hline Ago & argonaute \\
\hline anti-CCP & anti-cyclic citrullinated peptide \\
\hline CDK2 & cyclin-dependent kinase 2 \\
\hline GWBs & GW bodies \\
\hline IL & interleukin \\
\hline IRAK1 & IL-1 receptor-associated kinase 1 \\
\hline LPS & lipopolysaccharide \\
\hline MCP-1 & monocyte chemoattractant protein 1 \\
\hline miRNAs & microRNAs \\
\hline MMPs & matrix metalloproteinases \\
\hline mRNA & messenger RNA \\
\hline NF-kB & nuclear factor kappa-light-chain-enhancer of activated B cells \\
\hline PBMCs & peripheral blood mononuclear cells \\
\hline pre-miRNA & precursor miRNA \\
\hline pri-miRNA & primary miRNA \\
\hline $\mathbf{R A}$ & rheumatoid arthritis \\
\hline RAFLS & RA fibroblast-like synoviocytes \\
\hline RISC & RNA-induced silencing complex \\
\hline Th & T helper \\
\hline TLR & Toll-like receptor \\
\hline TNF & tumor necrosis factor \\
\hline TRAF6 & tumor necrosis factor receptor-associated factor 6 \\
\hline UTR & untranslated region \\
\hline
\end{tabular}

\section{References}

1. Klareskog L, Catrina AI, Paget S. Rheumatoid arthritis. Lancet. 2009; 373:659-72. [PubMed: 19157532]

2. Firestein GS. Evolving concepts of rheumatoid arthritis. Nature. 2003; 423:356-61. [PubMed: 12748655]

3. Bukhari M, Lunt M, Harrison BJ, Scott DG, Symmons DP, Silman AJ. Rheumatoid factor is the major predictor of increasing severity of radiographic erosions in rheumatoid arthritis: results from the Norfolk Arthritis Register Study, a large inception cohort. Arthritis Rheum. 2002; 46:906-12. [PubMed: 11953966]

4. Zendman AJ, van Venrooij WJ, Pruijn GJ. Use and significance of anti-CCP autoantibodies in rheumatoid arthritis. Rheumatology. 2006; 45:20-5. [PubMed: 16188946] 
5. De Rycke L, et al. Rheumatoid factor and anticitrullinated protein antibodies in rheumatoid arthritis: diagnostic value, associations with radiological progression rate, and extra-articular manifestations. Ann Rheum Dis. 2004; 63:1587-93. [PubMed: 15547083]

6. Schellekens GA, de Jong BA, van den Hoogen FH, van de Putte LB, van Venrooij WJ. Citrulline is an essential constituent of antigenic determinants recognized by rheumatoid arthritis-specific autoantibodies. J Clin Invest. 1998; 101:273-81. [PubMed: 9421490]

7. McInnes IB, Schett G. Cytokines in the pathogenesis of rheumatoid arthritis. Nat Rev Immunol. 2007; 7:429-42. [PubMed: 17525752]

8. Choy EH, Panayi GS. Cytokine pathways and joint inflammation in rheumatoid arthritis. N Engl J Med. 2001; 344:907-16. [PubMed: 11259725]

9. Listing J, et al. Infections in patients with rheumatoid arthritis treated with biologic agents. Arthritis Rheum. 2005; 52:3403-12. [PubMed: 16255017]

10. Gomez-Reino JJ, Carmona L, Valverde VR, Mola EM, Montero MD. Treatment of rheumatoid arthritis with tumor necrosis factor inhibitors may predispose to significant increase in tuberculosis risk: a multicenter active-surveillance report. Arthritis Rheum. 2003; 48:2122-7. [PubMed: 12905464]

11. Askling J, Bongartz T. Malignancy and biologic therapy in rheumatoid arthritis. Curr Opin Rheumatol. 2008; 20:334-9. [PubMed: 18388527]

12. Baltimore D, Boldin MP, O’Connell RM, Rao DS, Taganov KD. MicroRNAs: new regulators of immune cell development and function. Nat Immunol. 2008; 9:839-45. [PubMed: 18645592]

13. Ambros V, et al. A uniform system for microRNA annotation. RNA. 2003; 9:277-9. [PubMed: 12592000]

14. Pauley KM, Cha S, Chan EKL. MicroRNA in autoimmunity and autoimmune diseases. J Autoimmun. 2009; 32:189-94. [PubMed: 19303254]

15. Han J, Lee Y, Yeom KH, Kim YK, Jin H, Kim VN. The Drosha-DGCR8 complex in primary microRNA processing. Genes Dev. 2004; 18:3016-27. [PubMed: 15574589]

16. Berezikov E, Chung WJ, Willis J, Cuppen E, Lai EC. Mammalian mirtron genes. Mol Cell. 2007; 28:328-36. [PubMed: 17964270]

17. Liu J, et al. Argonaute2 is the catalytic engine of mammalian RNAi. Science. 2004; 305:1437-41. [PubMed: 15284456]

18. Eystathioy T, Chan EKL, Tenenbaum SA, Keene JD, Griffith K, Fritzler MJ. A phosphorylated cytoplasmic autoantigen, GW182, associates with a unique population of human mRNAs within novel cytoplasmic speckles. Mol Biol Cell. 2002; 13:1338-51. [PubMed: 11950943]

19. Zhou H, Huang X, Cui H, Luo X, Tang Y, Chen S, Wu L, Shen N. miR-155 and its star-form partner miR-155* cooperatively regulate type I interferon production by human plasmacytoid dendritic cells. Blood. 2010; 116:5885-94. [PubMed: 20852130]

20. Babiarz JE, Ruby JG, Wang Y, Bartel DP, Blelloch R. Mouse ES cells express endogenous shRNAs, siRNAs, and other Microprocessor-independent, Dicer-dependent small RNAs. Genes Dev. 2008; 22:2773-85. [PubMed: 18923076]

21. Cifuentes D, et al. A novel miRNA processing pathway independent of Dicer requires Argonaute2 catalytic activity. Science. 2010; 328:1694-8. [PubMed: 20448148]

22. Krol J, Loedige I, Filipowicz W. The widespread regulation of microRNA biogenesis, function and decay. Nat Rev Genet. 2010; 11:597-610. [PubMed: 20661255]

23. Jakymiw A, et al. The role of GW/P-bodies in RNA processing and silencing. J Cell Sci. 2007; 120:1317-23. [PubMed: 17401112]

24. Lian SL, Li S, Abadal GX, Pauley BA, Fritzler MJ, Chan EKL. The C-terminal half of human Ago2 binds to multiple GW-rich regions of GW182 and requires GW182 to mediate silencing. RNA. 2009; 15:804-13. [PubMed: 19324964]

25. Yao B, Li S, Jung HM, Lian SL, Abadal GX, Han F, Fritzler MJ, Chan EKL. Divergent GW182 functional domains in the regulation of translational silencing. Nucleic Acids Res. 2011; 39:253447. [PubMed: 21131274]

26. Yang Z, Jakymiw A, Wood MR, Eystathioy T, Rubin RL, Fritzler MJ, Chan EKL. GW182 is critical for the stability of GW bodies expressed during the cell cycle and cell proliferation. J Cell Sci. 2004; 117:5567-78. [PubMed: 15494374] 
27. Jakymiw A, Ikeda K, Fritzler MJ, Reeves WH, Satoh M, Chan EKL. Autoimmune targeting of key components of RNA interference. Arthritis Res Ther. 2006; 8:R87. [PubMed: 16684366]

28. Bhanji RA, Eystathioy T, Chan EKL, Bloch DB, Fritzler MJ. Clinical and serological features of patients with autoantibodies to GW/P bodies. Clin Immunol. 2007; 125:247-56. [PubMed: 17870671]

29. Lian S, Fritzler MJ, Katz J, Hamazaki T, Terada N, Satoh M, Chan EKL. Small interfering RNAmediated silencing induces target-dependent assembly of GW/P bodies. Mol Biol Cell. 2007; 18:3375-87. [PubMed: 17596515]

30. Pauley KM, Eystathioy T, Jakymiw A, Hamel JC, Fritzler MJ, Chan EKL. Formation of GW bodies is a consequence of microRNA genesis. EMBO Rep. 2006; 7:904-10. [PubMed: 16906129]

31. Pauley KM, et al. Formation of GW/P bodies as marker for microRNA-mediated regulation of innate immune signaling in THP-1 cells. Immunol Cell Biol. 2010; 88:205-12. [PubMed: 19918258]

32. Eulalio A, Behm-Ansmant I, Schweizer D, Izaurralde E. P-body formation is a consequence, not the cause, of RNA-mediated gene silencing. Mol Cell Biol. 2007; 27:3970-81. [PubMed: 17403906]

33. Bartel DP. MicroRNAs: target recognition and regulatory functions. Cell. 2009; 136:215-33. [PubMed: 19167326]

34. Filipowicz W, Bhattacharyya SN, Sonenberg N. Mechanisms of post-transcriptional regulation by microRNAs: are the answers in sight? Nat Rev Genet. 2008; 9:102-14. [PubMed: 18197166]

35. Orom UA, Nielsen FC, Lund AH. MicroRNA-10a binds the 5'UTR of ribosomal protein mRNAs and enhances their translation. Mol Cell. 2008; 30:460-71. [PubMed: 18498749]

36. Tay Y, Zhang J, Thomson AM, Lim B, Rigoutsos I. MicroRNAs to Nanog, Oct4 and Sox 2 coding regions modulate embryonic stem cell differentiation. Nature. 2008; 455:1124-8. [PubMed: 18806776]

37. Duursma AM, Kedde M, Schrier M, le Sage C, Agami R. miR-148 targets human DNMT3b protein coding region. RNA. 2008; 14:872-7. [PubMed: 18367714]

38. Pan W, et al. MicroRNA-21 and microRNA-148a contribute to DNA hypomethylation in lupus CD4+ T cells by directly and indirectly targeting DNA methyltransferase 1. J Immunol. 2010; 184:6773-81. [PubMed: 20483747]

39. Shin C, Nam JW, Farh KK, Chiang HR, Shkumatava A, Bartel DP. Expanding the microRNA targeting code: functional sites with centered pairing. Mol Cell. 2010; 38:789-802. [PubMed: 20620952]

40. Friedman RC, Farh KK, Burge CB, Bartel DP. Most mammalian mRNAs are conserved targets of microRNAs. Genome Res. 2009; 19:92-105. [PubMed: 18955434]

41. Mansfield KD, Keene JD. The ribonome: a dominant force in coordinating gene expression. Biol Cell. 2009; 101:169-81. [PubMed: 19152504]

42. Chi SW, Zang JB, Mele A, Darnell RB. Argonaute HITS-CLIP decodes microRNA-mRNA interaction maps. Nature. 2009; 460:479-86. [PubMed: 19536157]

43. Hafner M, et al. Transcriptome-wide identification of RNA-binding protein and microRNA target sites by PAR-CLIP. Cell. 2010; 141:129-41. [PubMed: 20371350]

44. Guo H, Ingolia NT, Weissman JS, Bartel DP. Mammalian microRNAs predominantly act to decrease target mRNA levels. Nature. 2010; 466:835-40. [PubMed: 20703300]

45. Duroux-Richard I, Presumey J, Courties G, Gay S, Gordeladze J, Jorgensen C, Kyburz D, Apparailly F. MicroRNAs as new player in rheumatoid arthritis. Joint Bone Spine. 2011; 78:1722. [PubMed: 20864373]

46. Li L, Chen XP, Li YJ. MicroRNA-146a and human disease. Scand J Immunol. 2010; 71:227-31. [PubMed: 20384865]

47. Kozomara A, Griffiths-Jones S. miRBase: integrating microRNA annotation and deep-sequencing data. Nucleic Acids Res. 2011; 39:D152-7. [PubMed: 21037258]

48. Taganov KD, Boldin MP, Chang KJ, Baltimore D. NF-kappaB-dependent induction of microRNA miR-146, an inhibitor targeted to signaling proteins of innate immune responses. Proc Natl Acad Sci U S A. 2006; 103:12481-6. [PubMed: 16885212] 
49. Liew FY, Xu D, Brint EK, O’Neill LA. Negative regulation of toll-like receptor-mediated immune responses. Nat Rev Immunol. 2005; 5:446-58. [PubMed: 15928677]

50. Cavaillon JM, Adib-Conquy M. Bench-to-bedside review: endotoxin tolerance as a model of leukocyte reprogramming in sepsis. Crit Care. 2006; 10:233. [PubMed: 17044947]

51. McCall CE, Grosso-Wilmoth LM, LaRue K, Guzman RN, Cousart SL. Tolerance to endotoxininduced expression of the interleukin-1 beta gene in blood neutrophils of humans with the sepsis syndrome. J Clin Invest. 1993; 91:853-61. [PubMed: 7680670]

52. Nahid MA, Pauley KM, Satoh M, Chan EKL. miR-146a is critical for endotoxin-induced tolerance: Implication in innate immunity. J Biol Chem. 2009; 284:34590-9. [PubMed: 19840932]

53. Nahid MA, Satoh M, Chan EKL. Mechanistic Role of MicroRNA-146a in Endotoxin-Induced Differential Cross-Regulation of TLR Signaling. J Immunol. 2011; 186:1723-34. [PubMed: 21178010]

54. Kumar H, Kawai T, Akira S. Pathogen recognition by the innate immune system. Int Rev Immunol. 2011; 30:16-34. [PubMed: 21235323]

55. Casanova JL, Abel L, Quintana-Murci L. Human TLRs and IL-1Rs in Host Defense: Natural Insights from Evolutionary, Epidemiological, and Clinical Genetics. Annu Rev Immunol. 2011; 29:447-91. [PubMed: 21219179]

56. Biswas SK, et al. Role for MyD88-independent, TRIF pathway in lipid A/TLR4-induced endotoxin tolerance. J Immunol. 2007; 179:4083-92. [PubMed: 17785847]

57. Adib-Conquy M, Cavaillon JM. Compensatory anti-inflammatory response syndrome. Thromb Haemost. 2009; 101:36-47. [PubMed: 19132187]

58. Nahid MA, Rivera M, Lucas A, Chan EKL, Kesavalu L. Polymicrobial Infection with Periodontal Pathogens Specifically enhances miR-146a in ApoE-/- Mice during Experimental Periodontal Disease. Infect Immun. 2011; 79:1597-605. [PubMed: 21263019]

59. Mercado FB, Marshall RI, Bartold PM. Inter-relationships between rheumatoid arthritis and periodontal disease. A review. J Clin Periodontol. 2003; 30:761-72. [PubMed: 12956651]

60. Marotte H, Farge P, Gaudin P, Alexandre C, Mougin B, Miossec P. The association between periodontal disease and joint destruction in rheumatoid arthritis extends the link between the HLADR shared epitope and severity of bone destruction. Ann Rheum Dis. 2006; 65:905-9. [PubMed: 16284099]

61. de Pablo P, Dietrich T, McAlindon TE. Association of periodontal disease and tooth loss with rheumatoid arthritis in the US population. J Rheumatol. 2008; 35:70-6. [PubMed: 18050377]

62. Hitchon CA, et al. Antibodies to porphyromonas gingivalis are associated with anticitrullinated protein antibodies in patients with rheumatoid arthritis and their relatives. J Rheumatol. 2010; 37:1105-12. [PubMed: 20436074]

63. McGraw WT, Potempa J, Farley D, Travis J. Purification, characterization, and sequence analysis of a potential virulence factor from Porphyromonas gingivalis, peptidylarginine deiminase. Infect Immun. 1999; 67:3248-56. [PubMed: 10377098]

64. Curtale G, et al. An emerging player in the adaptive immune response: microRNA-146a is a modulator of IL-2 expression and activation-induced cell death in T lymphocytes. Blood. 2010; 115:265-73. [PubMed: 19965651]

65. Lu LF, et al. Function of miR-146a in controlling Treg cell-mediated regulation of Th1 responses. Cell. 2010; 142:914-29. [PubMed: 20850013]

66. Arnett FC, et al. The American Rheumatism Association 1987 revised criteria for the classification of rheumatoid arthritis. Arthritis Rheum. 1988; 31:315-24. [PubMed: 3358796]

67. van der Linden MP, Knevel R, Huizinga TW, van der Helm-van Mil AH. Classification of rheumatoid arthritis: comparison of the 1987 American College of Rheumatology criteria and the 2010 American College of Rheumatology/European League Against Rheumatism criteria. Arthritis Rheum. 2011; 63:37-42. [PubMed: 20967854]

68. Wittmann J, Jack HM. microRNAs in rheumatoid arthritis: midget RNAs with a giant impact. Ann Rheum Dis. 2011; 70(Suppl 1):i92-6. [PubMed: 21339228]

69. Pauley KM, Satoh M, Chan AL, Bubb MR, Reeves WH, Chan EKL. Upregulated miR-146a expression in peripheral blood mononuclear cells from rheumatoid arthritis patients. Arthritis Res Ther. 2008; 10:R101. [PubMed: 18759964] 
70. Nakasa T, Miyaki S, Okubo A, Hashimoto M, Nishida K, Ochi M, Asahara H. Expression of microRNA-146 in rheumatoid arthritis synovial tissue. Arthritis Rheum. 2008; 58:1284-92. [PubMed: 18438844]

71. Stanczyk J, et al. Altered expression of MicroRNA in synovial fibroblasts and synovial tissue in rheumatoid arthritis. Arthritis Rheum. 2008; 58:1001-9. [PubMed: 18383392]

72. Nakasa T, Shibuya H, Nagata Y, Niimoto T, Ochi M. The inhibitory effect of microRNA-146 expression on bone destruction in arthritis. Arthritis Rheum. 2011

73. Li J, et al. Altered microRNA expression profile with miR-146a upregulation in CD4+ T cells from patients with rheumatoid arthritis. Arthritis Res Ther. 2010; 12:R81. [PubMed: 20459811]

74. Yamasaki K, et al. Expression of MicroRNA-146a in osteoarthritis cartilage. Arthritis Rheum. 2009; 60:1035-41. [PubMed: 19333945]

75. Li X, Gibson G, Kim JS, Kroin J, Xu S, van Wijnen AJ, Im HJ. MicroRNA-146a is linked to painrelated pathophysiology of osteoarthritis. Gene. 2011

76. Chatzikyriakidou A, Voulgari PV, Georgiou I, Drosos AA. A polymorphism in the 3'-UTR of interleukin-1 receptor-associated kinase (IRAK1), a target gene of miR-146a, is associated with rheumatoid arthritis susceptibility. Joint Bone Spine. 2010; 77:411-3. [PubMed: 20870441]

77. Nakamachi Y, et al. MicroRNA-124a is a key regulator of proliferation and monocyte chemoattractant protein 1 secretion in fibroblast-like synoviocytes from patients with rheumatoid arthritis. Arthritis Rheum. 2009; 60:1294-304. [PubMed: 19404929]

78. Alsaleh G, et al. Bruton's tyrosine kinase is involved in miR-346-related regulation of IL-18 release by lipopolysaccharide-activated rheumatoid fibroblast-like synoviocytes. J Immunol. 2009; 182:5088-97. [PubMed: 19342689]

79. Fulci V, et al. miR-223 is overexpressed in T-lymphocytes of patients affected by rheumatoid arthritis. Hum Immunol. 2010; 71:206-11. [PubMed: 19931339]

80. Stanczyk J, et al. Altered expression of miR-203 in rheumatoid arthritis synovial fibroblasts and its role in fibroblast activation. Arthritis Rheum. 2011; 63:373-81. [PubMed: 21279994]

81. Karouzakis E, Gay RE, Gay S, Neidhart M. Epigenetic control in rheumatoid arthritis synovial fibroblasts. Nat Rev Rheumatol. 2009; 5:266-72. [PubMed: 19412193]

82. Brooks WH, Le Dantec C, Pers JO, Youinou P, Renaudineau Y. Epigenetics and autoimmunity. J Autoimmun. 2010; 34:J207-19. [PubMed: 20053532]

83. Horiuchi M, Morinobu A, Chin T, Sakai Y, Kurosaka M, Kumagai S. Expression and function of histone deacetylases in rheumatoid arthritis synovial fibroblasts. J Rheumatol. 2009; 36:1580-9. [PubMed: 19531758]

84. Huber LC, et al. Histone deacetylase/acetylase activity in total synovial tissue derived from rheumatoid arthritis and osteoarthritis patients. Arthritis Rheum. 2007; 56:1087-93. [PubMed: 17393417]

85. Karouzakis E, Gay RE, Michel BA, Gay S, Neidhart M. DNA hypomethylation in rheumatoid arthritis synovial fibroblasts. Arthritis Rheum. 2009; 60:3613-22. [PubMed: 19950268]

86. Alevizos I, Illei GG. MicroRNAs as biomarkers in rheumatic diseases. Nat Rev Rheumatol. 2010; 6:391-8. [PubMed: 20517293]

87. Niimoto T, et al. MicroRNA-146a expresses in interleukin-17 producing T cells in rheumatoid arthritis patients. BMC Musculoskelet Disord. 2010; 11:209. [PubMed: 20840794]

88. Murata K, Yoshitomi H, Tanida S, Ishikawa M, Nishitani K, Ito H, Nakamura T. Plasma and synovial fluid microRNAs as potential biomarkers of rheumatoid arthritis and osteoarthritis. Arthritis Res Ther. 2010; 12:R86. [PubMed: 20470394] 
- MicroRNAs play an important role in immunity and inflammation.

- Aberrant expression of miRNAs reported in rheumatoid arthritis may lead to the inflammatory milieu in the pathogenesis.

- The increased expression of miR-146a in several cell types has beenconsistently reported in rheumatoid arthritis.

- MicroRNAs may become new diagnostic markers and therapeutic targets in rheumatoid arthritis. 


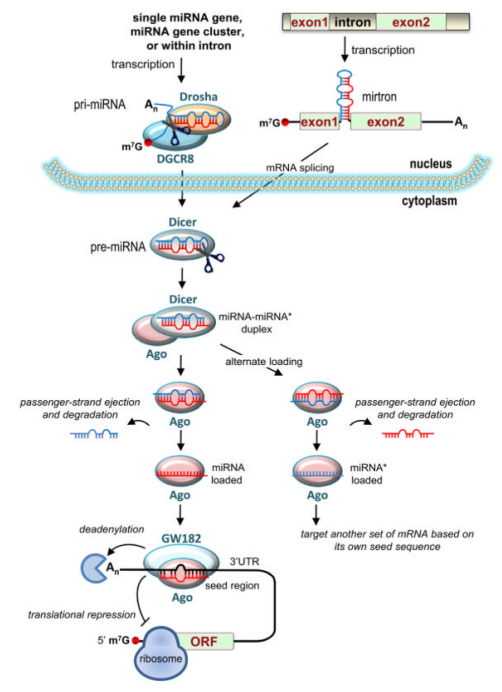

Fig. 1. Biogenesis of miRNAs and their effect on mRNA targets See text for detailed description. The primary miRNA (pri-miRNA) is transcribed from respective gene(s) and is processed in the nucleus by Drosha/DGCR8, to precursor miRNA (pre-miRNA). The latter is transported to the cytoplasm and further processed to mature miRNA. Through the interaction with Ago and GW182, the mature miRNA is able to exert its translational silencing function on specific mRNA target(s). Alternative pathways exist for the miRNA biogenesis (the "mirtron" formation) and selection for the miRNA* strand. 


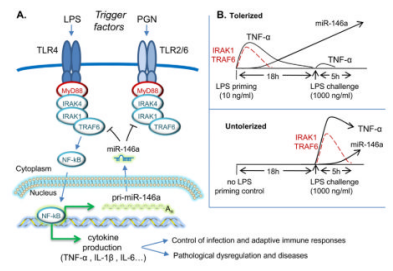

Fig. 2. Role of miR-146a in endotoxin-induced tolerance and cross-tolerance Panel A, MyD88-dependent TLR signaling pathway is regulated by miR-146a. Lipopolysaccharide (LPS) and peptidoglycan (PGN) activate immune cells through interaction with the TLR (TLR4, TLR 2/6) complex on the cell surface. This leads to the activation of the MyD88 dependent pathway, followed by the sequential recruitment of IRAK4, IRAK1, and TRAF6, and eventual activation of NF- $\kappa$ B. The active NF- $\kappa B$ is then exported to the nucleus where it activates the expression of pro-inflammatory cytokines, such as TNF- $\alpha$ and IL-1 $\beta$. This pathway is normally used to control the growth and dissemination of the infectious agent and to activate the immune response as needed. However, if this mechanism is altered, the result is the pathological dysregulation leading to disease, as in the case of sepsis, multiorgan failure, autoimmune disease, or cancer. When $\mathrm{NF}-\kappa \mathrm{B}$ is activated, it also leads to the transcription of pri-miR146a and eventual maturation to miR-146a, which targets and down-regulates IRAK1 and TRAF6 through translational repression and degradation of mRNA. In the presence of LPS, miR-146a can increase up to 100 fold greater compared to untreated control monocytes. This negative feedback mechanism is induced by the high level of miR-146a, and it suppresses the expression of IRAK1 and TRAF6. In this way, the cell is able to enter a state of tolerance against further stimulation by LPS or many other TLR ligands.

Panel B is a schematic of the relative expression of TNF- $\alpha$, IRAK1/TRAF6, and miR-146a in the LPS-induced tolerance using the THP-1 cell model [52,53], in which tolerized cells quickly produce TNF- $\alpha$, which continues for about 4-6 hours. When TNF- $\alpha$ production decreases, miR-146a starts to increase. Eighteen hours post-priming, a large difference is observed between TNF- $\alpha$ and miR-146a, as miR-146a acts negatively on IRAK1 and TRAF6 and the cells become tolerized. Tolerized cells do not respond to even higher dose of LPS challenge, due to the high levels of miR-146a, while untolerized cells respond to the second LPS challenge with higher production of TNF- $\alpha$. 
Table 1

Aberrant microRNA expression reported in rheumatoid arthritis.

\begin{tabular}{|c|c|c|c|c|}
\hline Cell type & miRNA & Fold change & Documented or postulated effect & Ref \\
\hline PBMCs & $\begin{array}{c}\text { miR-146a, miR-155, } \\
\text { miR-132, miR-16 }\end{array}$ & $1.8-2.6 \uparrow$ & Prolonged TNF- $\alpha$ production & {$[69]$} \\
\hline PBMCs, synovial fibroblasts & miR-146a & $1.43-4 \uparrow$ & Regulation of TNF- $\alpha$ production & {$[69,71,86,87]$} \\
\hline Synovial fibroblasts & miR-203 & $8.9 \uparrow$ & $\begin{array}{c}\text { Increased MMPs production and } \\
\text { activation of the phenotype of synovial } \\
\text { fibroblasts }\end{array}$ & {$[80]$} \\
\hline $\begin{array}{c}\text { Synovial fibroblasts and synovial } \\
\text { tissue }\end{array}$ & miR-155 & $8 \uparrow$ & $\begin{array}{c}\text { Repression of MMPs production and } \\
\text { modulation of joint inflammation }\end{array}$ & {$[71]$} \\
\hline $\begin{array}{c}\text { Synovial tissue } \\
\text { RAR-146a, pri-miR-146a/b }\end{array}$ & $\mathrm{NR} \uparrow \uparrow$ & $\begin{array}{c}\text { Regulation of TNF- } \alpha \text { and IL-1 } 13 \\
\text { production }\end{array}$ & {$[70]$} \\
\hline RA fibroblast-like synoviocytes & miR-124a & $6.3 \downarrow$ & $\begin{array}{c}\text { Suppression of cell proliferation, } \\
\text { CDK2 and MCP-1 protein production }\end{array}$ & {$[77]$} \\
\hline CD4+ naïve T lymphocytes & miR-223 & $>7 \uparrow$ & $\begin{array}{c}\text { Indirect regulation of the pro- } \\
\text { inflammatory cytokine IL-18 }\end{array}$ & [78] \\
\hline
\end{tabular}

NR, exact fold change not reported. 


\section{Table 2}

MiRNA-146a detection in blood and tissue cells from rheumatoid arthritis patients.

\begin{tabular}{|c|c|c|c|}
\hline \multirow{4}{*}{ RA blood cells } & \multicolumn{3}{|c|}{ MiRNA-146a } \\
\cline { 2 - 4 } & Samples & Increased expression (fold change) & Ref \\
\cline { 2 - 4 } & PBMCs & 2.6 & {$[69]$} \\
\cline { 2 - 4 } & plasma & NR & {$[88]$} \\
\cline { 2 - 4 } & Th17 & 1.43 & {$[87]$} \\
\cline { 2 - 4 } & CD4+ T cells & $>2$ & {$[73]$} \\
\hline \multirow{3}{*}{ RA articular tissues } & FLS & 4 & {$[71]$} \\
\cline { 2 - 4 } & FLS & NR \\
\hline
\end{tabular}

FLS, fibroblast-like synoviocytes; NR, exact fold change not reported; PBMCs, peripheral blood monocytic cells. Increased levels of miR-146a are detected also in osteoarthritis cartilage (see text for details). 